\title{
Reflections on Conducting Community-Engaged Research During COVID-19
}

\section{Peter Duker}

\begin{abstract}
As an emerging scholar committed to social justice and anti-oppressive praxis, I entered my master's program in Geography at York University, Toronto, with the goal of contributing to new theoretical insights and meaningful outcomes for research participants in Thailand. While initially the concept of communityengaged research appeared to alleviate the tensions between these two goals, the realities of the university's constraints on graduate student research coupled with those of the COVID-19 pandemic have made it clear that this endeavor would not be straightforward. The inherent messiness of balancing academic matters (e.g., contributing to new theory and demonstrating an adequate level of rigor) with social justice concerns (e.g., eliminating epistemological violence and contributing meaningful outcomes for research participants) in community-engaged research has only intensified as COVID- 19 has reconfigured our social relations, exacerbating existing inequities and restricting our social mobility, particularly across international borders. In this reflection, I consider how remotely collaborating with local research assistants in my own graduate research project typifies these tensions. More specifically, I posit that the COVID-I9 pandemic has further underscored the importance of researchers, particularly white men researchers such as myself, to be willing to consistently re-evaluate our projects, and embrace flexibility, accountability, and the removal of ego from our work.
\end{abstract}

\section{Keywords}

collaborative methods, positionality, research assistants, COVID-19 


\section{Introduction}

Since entering graduate school with the goal of writing a master's thesis based on original research, I have needed to adapt my expectations to the realities and constraints of academia. After spending years abroad living and working alongside marginalized groups in West Africa and Southeast Asia, I began York University's graduate program in Geography perhaps a bit naively, albeit well-intentioned. My goal was, and continues to be, to conduct research that has meaningful outcomes for research participants. Familiar with the concept of 'community-engaged research', I saw the process of collaboratively working with research participants as a sort of 'silver bullet' to alleviate any potential ethical issues pertaining to the role of 'outsiders'. However, my original plans to achieve a mutually beneficial and collaborative process were upended by the COVID-19 pandemic. While COVID-19 is certainly unique, many of its challenges are ubiquitous in academic research, and underscore the existing tensions within community-engaged research. Accordingly, in this reflection, I invite the reader to consider the story of my research project as a testimony to the tensions inherent in well-meaning graduate student research projects. Drawing on my lived experiences with community engaged research and COVID-19, I make a case for privileged researchers, including myself, to embrace flexibility, accountability, and the removal of ego from their work.

My master's research project explores the emergence of community-based conservation areas on rivers in Northern Thailand, giving substantive focus to the economic and political potentialities of these actions for neighbouring Karen communities. ${ }^{1}$ This project arose from my experiences living and working in Thailand for five years, where I spent much of my time in rural areas working with the Karen and other ethnic minority groups. During my final year in Thailand, I was introduced to the people who later participated in my study while working as a research assistant for a colleague. We created surveys, and trained volunteers on how to record their daily fishing

\footnotetext{
${ }^{1}$ The Karen people are an ethnic minority group in Thailand, often derogatorily referred to as a 'hill tribe', who have historically experienced significant
}

activities in order to better understand the impacts of the riverine conservation areas created by these communities. From here, I saw the potential to further amplify the voices of the research participants as they resisted the threat of displacement posed by the incursion of a national park on their homelands. This is how I arrived at my master's research.

My time in these communities, and Thailand more broadly, muddles the insider-outsider dichotomy often present in transnational research. I have a level of understanding and familiarity with the culture, and a few locals with whom I am close, which allows me to somewhat bridge that gap. However, rather than dissolving the researcherresearch participant power dynamic typical to such work, I simply have a better view of the tensions that define and constrain it. I elaborate further on the value of such a perspective below.

\section{Flexibility}

When I began working on the methodology for my master's research proposal back in December of 2019, I was already struggling to balance the demand to produce 'rigorous' academic research with the ethical responsibility to remain adaptable to the preferences of research participants. Remaining cognizant of my past experiences in which I often noticed that these Karen community members would defer to my opinions (likely due to power imbalances), even though I wanted to hear from them, I was prepared to find ways to make sure the research was actually enriching their lives. Accordingly, I remained open to adapting my research methods as much as possible during my fieldwork.

Conducting fieldwork in situ (situated in the place, as opposed to remotely, for example) would have greatly facilitated my ability to notice and navigate cultural subtleties (e.g., non-verbal cues that indicate an underlying feeling or informal check-ins during mealtimes). This process of noticing and navigating is critical to understanding which aspects of the research or research process should be altered to meet the wants and needs of research participants. However, I cannot access my

marginalization, which continues to this day. See Delang (2004) or Laungaramsri (2003) for more information on the Karen people in Thailand. 
field sites due to the current health pandemic. National travel restrictions aside, the research participants refuse, and rightfully so, to let outsiders potentially infectious with COVID-19 into their communities. Due to many factors, including their remoteness and historic marginalization by the Thai state, these Karen communities lack access to the high-quality medical care needed to treat those who fall sick with the virus. Therefore, they have taken control of their situation by limiting the potential for exposure to the virus and denying outsiders access to their lands. The subsequent inability to conduct my research in-person has required me to completely adapt my research to remote methods. I am left trying to find ways to produce 'rigorous' research in order to satisfy my degree requirements, while also navigating how to engage remotely with communities on the other side of the world. Additionally, this all must occur within the strictly limited timeframe of a master's program; a challenge which is further exacerbated as I am an international student with limited funding opportunities to extend my studies. Yet, despite these challenges, I am still committed to conducting research that has meaningful outcomes for the research participants.

Adapting my research to remote methods has not been straightforward. While many academics have recently been encouraging the acceptance of remote methods for scholars looking for new ways to conduct research during COVID-19 (for a comprehensive compilation of materials, see Samuels, 2020), the majority of these strategies do not apply to my research, as they rely on a stable and consistent internet or cell network connection. The participants in my study reside in the mountain valleys of Northern Thailand where cell and internet connectivity are minimal, at best. Cellular networks (e.g., 3G or 5G) are only available in a few specific locations (e.g., on a mountain top) and are unreliable even in those locations due to factors such as weather conditions. There are some places with WIFI connection (e.g., some schools in the area), but the connection can also be unreliable. This means that participants would have to drive far distances to access signal or WIFI and the connection itself may not be strong enough for conducting research activities once they arrive. This is too heavy of a burden to place on them and it would also be very difficult to coordinate with more than a few participants.

However, I was extremely fortunate to have attended a conference in 2019 whereby a peer from my program, a doctoral candidate who has completed her fieldwork, presented on working with local research assistants to access areas otherwise inaccessible, such as how my sites have become. ${ }^{2}$ I reached out to her, and she has since become a vital source of support. She taught me how to work with local research assistants, which provided access that I would otherwise not have had. At the same time, this access comes with new power dynamics, which I further elaborate on below. Additionally, it must be noted that this fortunate encounter was itself a function of privilege. Not everyone interested in communityengaged research can attend conferences, either because they cannot afford to or because they do not have the time, or both. Furthermore, conferences can be exclusionary along racial and class lines, so even if marginalized students and researchers are able to attend, they may feel uncomfortable about doing so.

The inaccessibility of conferences and other academic resources has only gotten worse during the COVID-19 pandemic, with the increase of unemployment, food insecurity, police brutality, Sinophobia, anti-Black racism, and healthcare inaccessibility. COVID-19 has thus exacerbated the need for researchers to have preexisting social and cultural capital to mobilize. For me, this fact became most clear when I started searching for a local research assistant to work with. While it took a while, I connected with a potential candidate through the family that hosted me whenever I stayed in the village. Not only did they identify this candidate for me, but they also advocated for my integrity so that this person felt comfortable working with me. It took a great deal of trust for him to sign on to work with me-a foreigner whom he has neither met nor would be able to meet in person due to the pandemic (at least for now) - as a research assistant. Therefore, while flexibility

\footnotetext{
${ }^{2}$ See Roberts (2019) for a recent publication from this fieldwork.
} 
was critical to make my research project viable despite the aforementioned hurdles, it also must be simultaneously acknowledged that my pre-existing relationships with and experience in the communities were crucial to making remote research possible in this context.

\section{Accountability}

Before I continue narrating the story of the evolution of my research project, a brief academic interjection is required. In academic work, one must always 'justify' their methodology to their peers, regardless of any potentially meaningful material or symbolic benefit it may bring to the research participants. This step is essential to the completion of my thesis, and therefore degree; and without it, my research would not be considered 'valid'. Rather than withhold from the readers the same opportunity to hold me accountable, I present an abridged version over the next two paragraphs.

Over the past few decades, an increasing number of scholars have been interested in collaborative research methods, particularly feminist scholars (Sharp, 2005). Among such methods is the recruitment of and collaboration with local research assistants. While the definition of 'local' might vary from scholar to scholar, in the context of transnational research, 'local' implies someone from the country, if not the community of research participants itself.

From a postpositivist, or more traditional, academic perspective, the practice of sending 'untrained' (read as lacking a 'Western' education) research assistants to conduct research activities without the researcher physically present would be questioned. ${ }^{3}$ Such a practice invalidates the perception of 'objectivity' in research conduct and interpretation. However, I follow in the footsteps of many postmodern, critical race, and feminist scholars, in that I do not recognize the researcher as an 'objective' outside observer. Instead, the researcher, research assistant(s), and participant(s) all contribute to the research from their own 'partial perspective', in which embodied subjectivities (where one body can hold multiple subjectivities) offer particular insights into the world contingent on their positioning (Collins,

\footnotetext{
${ }^{3}$ The pervasiveness of this mindset is evident in the difficulties that I have faced in trying to get my research
}

2000). Coming from an understanding of 'partial perspectives', local research assistants enable new and deeper research insights, rather than barriers to mythic 'objectivity'. At this point, I will spare the reader from further theorizing, and leave them with this takeaway: academics willing to decenter themselves in the research process and uplift others, including local research assistants, as insightgenerating researchers in and of themselves, will enhance their research outcomes compared to those who do not. Accordingly, this is the approach I take in my work.

Academic rationalization aside, working with local research assistants helps my research contribute to social justice projects more meaningfully. By engaging local community members and other 'insiders' in the research process, we create opportunities "from the conception through the outcomes of the research" for local knowledges and priorities to be emphasized (Sharp, 2005, p. 307). In turn, collaborating with local research assistants has the potential to disrupt the typical hegemonic paradigm of extractive and exploitative research and to keep the research accountable to the communities we are studying. Thus, engaging with local research assistants facilitates a more mutually beneficial and reciprocal type of research with greater potential for growth and transformation.

These claims can be grounded in some examples from my own project. All of my engagements with community partners are mediated by the aforementioned local research assistant. This means that input by the local research assistant is provided at every stage of the project, and he dramatically shapes the project. With this comes the opportunity to include Karen cosmologies and to enable these cosmologies to shape my work. The local research assistant is from the community, and, from his discussions with other community members, is able to tell me what kinds of research outputs will directly assist them in their selfidentified challenges, specifically the challenge of insecure land rights due to the looming incursion of a national park.

Further, the local research assistant is also developing many new research skills that may help

funders to accept research assistants as a legitimate fieldwork cost. 
him and his community in the future. For instance, he has expressed the joy and excitement that he and the participants feel when they discuss the importance of the river in their lives for project activities. Here, the 'typical' power dynamic of traditional in-person research is upheaved as I am no longer present for the interviews and other participatory research activities. The hopeful part of me imagines that this new dynamic may provide a compelling model to level power relations between the researcher and research participants in a transnational community-engaged research context. However, I must also acknowledge that, despite the fact I am not physically located there with the research participants, I remain a "non-present and yet highly powerful actor." Unfortunately, the implications of this new power dynamic are very difficult, if not impossible, to gauge and fully understand. Therefore, I may never fully comprehend the impacts of this methodology, and whether it truly disrupts the typical researcherresearch participant power dynamic. Nonetheless, I still have hope, and place value in that feeling.

\section{Removal of Ego}

Importantly, the potential for mutually beneficial and reciprocal research is not guaranteed by undergoing collaborative research. The specificities of research design are contingent upon each project, and the researcher must be prepared to continually negotiate the tensions that remain, no matter the research design. These tensions are highlighted by Nagar (2002), who stresses that the need for the development of new theoretical insights, so that the researcher can advance their own career, must also be balanced with the need for knowledge production that disrupts hierarchies and hegemonies for the research subjects. The external validation needed for career advancement inevitably engages the ego as well, adding a personal dimension to these tensions, as our identity is often intertwined with our careers. I certainly feel the push and pull of these forces in regard to the theoretical, timing, and funding

\footnotetext{
${ }^{4}$ For these insightful words I give credit to Dr. Sarah Rotz at York University and extend my deep gratitude for her guidance in helping me to navigate the tensions in community-engaged academic work.

${ }^{5}$ See the following links for WHO reports, press releases, and a video that have been released highlighting the
}

constraints I encounter as a white man master's student - a person of privilege in a subordinated location - in addition to my ethical commitment to contribute to symbolic and material benefits for the research participants.

When researchers remove ego from their work, they will be more able to assess the various impacts of, and the degree to which they can reduce, academic harm. In my own research, the tensions between ego and ethics first emerged in the creation of my research proposal, but they perpetually exist as I continue to work on my thesis. While I would be happy to support any research that communities wish to undergo, the requirement to conduct research that develops new theoretical insights limits the extent of possible topics. For example, while land use and forest access issues are the most frequently cited concerns for Karen communities, scholars have been looking at these issues for decades now, and they are well understood, at least academically speaking. Therefore, a compromise was reached to instead look at their river management. Academics, and especially Southeast Asia-focused researchers, have historically examined community-based management of rivers much less prolifically, which indicates an opportunity for new research insights. My own research project is thus able to reconcile these juxtaposed interests between local communities and academics by examining the communities' management of their neighboring river, and to consider how this may help them in their struggle for land rights and self-determination. The wellmeaning researcher must let go of the egotistical desire to control every aspect of the research process, and instead, compromise and allow for participants and circumstances to guide the decisions and outcomes along the way.

I have also faced issues with the internal ethics review process at my university, which can be at odds with local realities. While the research participants' communities, and Thailand writ large, have done an effective job of mitigating the spread of COVID-19, ${ }^{5}$ York University's ethics office

advantages (and limitations) of Thailand's COVID-19 response: https://www.who.int/thailand/news/detail/1410-2020-Thailand-IAR-COVID19;

https://www.who.int/thailand/news/featurestories/detail/thailands-1-million-village-health- 
required a Canadian-based standard of COVID-19 precautions for all on-going research activities, regardless of the jurisdiction and local context. I am sure that the intentions were well-placed, and likely based on a concern for the health and safety of participants; however, the effect of this requirement is inherently neocolonial, as it inserts Canadian-based assumptions and practices about COVID-19 onto my research project, and that can undermine the efforts and agency of research participants. Fortunately, I was able to satisfy the office's requirements with a suitable alternative that recognizes the local context appropriately and works alongside existing community protocols, and my research was approved to continue. This instance illustrates how the inherent epistemological violence of research may be reduced by well-intentioned researchers, while also being thwarted, or at least exhausted, by the institutions in which they reside. ${ }^{6}$ Thus, while the question remains as to whether this violence is constitutive of research and therefore inevitable, removal of ego will assuredly help researchers to address this issue more purposively.

On a personal level, I have found it challenging to adjust to the slowness of the communityengaged research process. This has been especially exacerbated by my research context, and then again by the need to collaborate remotely. In the Global North, our neoliberal capitalist society places particular value on 'productivity', which has essentially been reduced to the quantity of tangible outputs produced over time. In this context, many of us may find ourselves in a 'rat race', focusing on our rate of 'production' (whatever that may be in our own specific cases) at the expense of our relationships (whether to our self or others). Despite my awareness of this situation, I (and I assume many of us) find it virtually impossible to escape from the societal pressure to conform to this modality. However, the Karen communities in which my research is based are rooted in other ways of knowing and being, whereby cultivating relationships is often of higher priority than producing tangible outputs or optimizing time.

volunteers-unsung-heroes-are-helping-guardcommunities-nationwide-from-covid-19

${ }^{6}$ It also seems prudent to point out that, as a white man with access to social and cultural capital, I am in a better
Adapting to a diametrical living and working style that prioritizes relationship building would be much more straightforward during in situ research, where the immersive experience is bound to force even the most stubborn of researchers to adapt. When working remotely, however, this is not the case. Let us think of this in terms of a hypothetical. For example, if the Karen communities were about to plant rice, I would not get any interviews done for the next two weeks. If I were in Thailand, that would be okay, as I would be able to engage with the community in other ways and still be physically present in their worlding. This hypothetical research-halting rice planting scenario did in fact happen while I was in Toronto, and I was stuck in the disconnect between physically existing in my immediate atmosphere of 'productivity' and the relatively slow-paced world of the villages in Thailand, thereby decelerating my research outputs. Although this was a blow to my productivityoriented ego, the sheer pertinacity of the dilemma eventually forced me to adjust. A primary way I did this was by 'getting over myself', so to speak, and focusing on how I could comprise and renegotiate my circumstances to benefit research participants, as opposed to mourning my ingrained need to be productive. This suggests that removal of ego is key for the well-meaning researcher to better address the tensions between the personal aspects of conducting research and the epistemological violence often present in academia.

\section{Re-evaluation}

All the tensions and constraints covered in this reflection have led and continue to lead to difficult decisions for my research design. How can I fully engage with and appreciate the wants and needs of local communities, while still fulfilling the requirements for my degree? Community-engaged research is (and should be) a time-consuming process, and community interests may be antithetical to typical academic requirements (e.g., 'new' theory, 'rigorous' methods, and so on). Administrative blueprints, such as acceptable research methods and ethics protocols, fail to account for local realities, and undermine other

position to (successfully) challenge my university than others. 
ways of being and knowing. While all of this was certainly apparent prior to the COVID-19 pandemic, these tensions have only been exacerbated since the crisis hit. Well-intentioned researchers may have to rely on preexisting sources of social, cultural, and economic capital to facilitate the research process, and they cannot count on their university or other funding institutions to support them adequately. Perhaps COVID-19 will force the academic world to reflect on how to contribute to anti-oppressive praxis more meaningfully. At minimum, researchers, and particularly white men researchers such as myself, clearly need to embrace flexibility, accountability, and removal of ego from our work in order for us to continue to create meaningful research during the pandemic. That being said, the real need is for this change to occur beyond this moment, and for researchers to have the general willingness to consistently pause their work and reconsider if its impacts are just-we need to commit to confronting the latent epistemological violence within the communityengaged research we hold dear. If COVID-19 has taught us anything, it should be the importance of re-evaluating our roles in perpetuating 'business as usual'. 


\section{References}

Delang, C. (2004). Living at the Edge of Thai Society: The Karen in the Highlands of Northern Thailand. London: Routledge.

Collins, P. H. (2000). Black Feminist Thought: Knowledge, Consciousness, and the Politics of Empowerment (Revised 10th Anniversary Edition). New York; London: Routledge.

Laungaramsri, P. (2003). Ethnicity and the politics of ethnic classification in Thailand. In Mackerras, C. (Eds.) Ethnicity in Asia (157174). London; New York: Taylor and Francis. Nagar, R. (2002). Footloose Researchers, "Traveling" Theories, and the Politics of Transnational Feminist Praxis. Gender, Place \& Culture, 9(2), $179-186$.

Roberts, K. B. (2019). Powers of Access: Impacts on Resource Users and Researchers in Myanmar's Shan State. In Middleton, C., \& Lamb, V. (Eds.) Knowing the Salween River: Resource Politics of a Contested Transboundary River (205 - 221). Springer International Publishing. https://doi.org/10.1007/978-3-319-77440-4

Samuels, F. (2020, June). Tips for collecting primary data in a Covid-19 era. Retrieved on August, 2020.

https://www.odi.org/publications/16977primary-data-collection-covid-19-era

Sharp, J. (2005). Geography and gender: Feminist methodologies in collaboration and in the field. Progress in Human Geography, 29(3), $304-309$.

\section{Acknowledgements}

This reflection paper emerges out of research funded by the York Center for Asian Research (YCAR) and the Faculty of Graduate Studies at York University. I give many thanks to Kimberly Roberts for all of her critical advice about working with local research assistants, to Dr. Sarah Rotz for helping me to navigate the tensions in community-engaged academic work, and to the editors of this journal for all of their incredibly valuable comments, critiques, and edits. My appreciation also goes out to Carli Melo and Katie Duker for their helpful edits of earlier drafts of this paper.

\section{Author Biography}

Peter Duker is an MA student in the Geography program at York University's Faculty of Environmental and Urban Change. His research utilizes a political ecology approach to study the intersections of livelihoods, conservation, and development. Peter's current work includes his MA thesis on the establishment of riverine conservation areas by ethnic Karen communities in Northwestern Thailand. He also contributes to the Work at Sea project at York University, investigating the working conditions and labour relations among migrant workers in industrial fisheries and the seafood sector in Asia, particularly Thailand. Peter has been an educator for many years working as a teaching assistant at York University, a study abroad instructor at the International Sustainable Development Studies Institute in Thailand, and a secondary-level physics teacher in Sierra Leone. He received his BA in Environmental Science and Physics in 2013 from Colorado College. He can be contacted at pduker@yorku.ca for any inquiries. 